\title{
Mor Çiçekli Orman Gülünün dokuz yıllık boy ve çap artımının meşcere kapalılık derecesine göre değişimi
}

\author{
Change of nine-year length and diameter increase of Common Rhododendron according to the degree of stand canopy \\ closure
}

\section{Mimar Sinan ÖZKAYA}

Orman Genel Müdürlüğü, Artvin Orman Bölge Müdürlüğü, Artvin.

Eser Bilgisi / Article Info

Araştırma makalesi / Research article

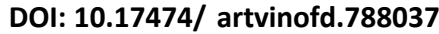

Sorumlu yazar / Corresponding author

Mimar Sinan ÖZKAYA

e-mail: mimarsinanozkaya@ogm.gov.tr

Geliş tarihi / Received

30.08.2020

Düzeltme tarihi / Received in revised form

10.09.2020

Kabul Tarihi / Accepted

14.09.2020

Elektronik erişim / Online available

18.09.2020

Anahtar kelimeler:

Diri örtü

Doğu ladini

Orman gülü

Kapalılık

Yıllık artım

Keywords:

Weed

Oriental spruce

Rhododendron

Canopy closure

Annual increment

\section{Özet}

Bu çalışmada, Artvin Merkez Orman İşletme Müdürlüğünde bulunan Doğu ladini (Picea orientalis L) meşcereleri altında bulunan Mor Çiçekli Ormangülü (Rhododenron ponticum L.) bitkisinin farklı kapalılık derecesine kapalııktaki (tam kapalı, orta kapalı ve gevşek kapalı) sahip orman alanlarındaki büyüme potansiyeli araştırılmıştır. Bu amaçla Artvin Orman İşletme Müdürlüğü sınırları içerisindeki farklı kapalılık derecesine sahip Doğu Ladini meşcerelerinin alt tabakasında daha önceden biyokütle amacıyla ormangülünün toprak seviyesinden temizlendiği meşcerelerden toplam 49 adet $25 \mathrm{~m}^{2}(5 \mathrm{~m}$ $x 5 \mathrm{~m}$ ) büyüklüğünde örnekleme alanı belirlenmiştir. Belirlenen örnekleme alanlarında orman gülü sürgünlerinde çap ve boy ölçümleri gerçekleştirilmiştir. Çalışma sonucunda yıllık çap artımı ve yıllık boy artımı değerlerinin kapalııık derecesinin artışına bağlı olarak azaldığı $(p<0.05)$ tespit edilmiştir. Gevşek kapalı meşcerelerde çap ve boy artımının daha fazla olması, Orman gülünün diri örtü olarak sorun oluşturmaması için ormanların kapalılı̆ının fazla kırılmaması gerektiğini göstermektedir.

\begin{abstract}
In this study, the growth potential of Common Rhododendron (Rhododenron ponticum L.) under the Oriental spruce (Picea orientalis L.) stands in Artvin Central Forest Management Directorate in forest areas with different degrees of canopy closure (fully closed, medium closed and loose closed) was investigated. For this purpose, a total of 49 sampling areas of $25 \mathrm{~m}^{2}(5 \mathrm{~m} \times 5 \mathrm{~m})$ were determined in the lower layer of the Eastern Spruce stands within the boundaries of the Artvin Forest Management Directorate, where rhododendron was previously cleared from the soil level for biomass. Diameter and height measurements of rhododendron shoots were carried out in the determined sampling areas. As a result of the study, it was determined that the annual diameter increase and annual height increase values decreased $(p<0.05)$ depending on the increase in the degree of canopy closure. The higher diameter and height increase in loosely closed stands indicates that the canopy of the forests should not be broken much so that the rhododendron does not cause a problem as a weed.
\end{abstract}

\section{GiRiş}

Ormangülleri, Doğu Karadeniz ormanlarında ve orman içi açıklıklarında diri örtü olarak en fazla bulunan bitki türleridir (Küçük 2005). Doğu Karadeniz ormanlarında en sık rastlanılan orman güllerine deniz seviyesinden $5000 \mathrm{~m}$ yüksekliğe sahip dağ bölgelerine kadar rastlamak mümkündür (Suzuki ve Ohba 1988, Avcı 2004).

Orman gülleri cinsinin bir üyesi olan mor çiçekli ormangülü (Rhododendron ponticum L.) Belçika, Bulgaristan, Fransa, İngiltere, İrlanda, İspanya, Kafkaslar,
Lübnan ve Portekiz'de de yayılış göstermektedir (Robinson ve ark. 1980, Clay ve ark. 1992, Çolak 1997). Ülkemizde, Doğu Karadeniz Bölgesinin en kuzey kısmı olan Artvin ilinde başlayan yayılışı batıda Trakya Bölgesinde Istranca dağlarının kuzey yamaçlarına kadar uzanmaktadır (Stewens 1978). Mor çiçekli orman gülü uygun koşullarda 6-7 $\mathrm{m}$ boy ve $35-40 \mathrm{~cm}$ çap yapabilmektedir (Çolak 1997).

Diri örtünün durumu alandaki ağaç gelişimlerinde farklı etkilere neden olabilir. Şöyle ki; diri örtünün yaşı ve 
yüksekliğine göre kapladığı yüzey artmakta ve alandaki otsu türler, çalılar ile arasında rekabet söz konusu olmaktadır. Otsu türlerin hızlı büyümesi ilk etapta çalımsı türleri baskılasa da daha sonrasında çalımsı türlerin büyüyerek alanda üstünlük sağlamaktadır. Bu durumda diri örtünün çeşitliliği gerek toprağın gölgelenmesini gerekse organik madde yapısını önemli derecede etkilemektedir (Jianwei ve ark. 2015).

Diri örtünün oluşum ve gelişiminde kapalılığın önemli bir etkisi vardır. Azalan kapalıııkla birlikte meşcere tabanına ulanan ışık miktarının artması diri örtü oluşumu için uygun koşullar hazırlamaktadır. Thomas (2015), Cornus stolonifera, Oplopanax horridus, Rubus parviflorus, Shepherdia canadenis ve Vaccinium membranaceum türlerinin bir arada olduğunda \% 40 - 90 güneş ışı̆̆ında en iyi büyüme gerçekleştirdiklerini belirlemiştir. Bununla birlikte kapalılığın azalmasıyla diri örtünün boy gelişimlerinde de artışlar meydana gelmektedir (Montane ve ark. 2016). Işık yoğunluğunun artmasıyla birlikte diri örtü gelişiminde görülen bu gelişme, tohumların toprağa ulaşması, uygun çimlenme yataklarının oluşması ve fideciklerin gelişimi için gerekli olan koşulların oluşması açısından olumsuz etkiler oluşturmaktadır. Gençleştirme alanında bulunan diri örtü özellikle Karadeniz bölgesinde yavaş büyüyen ladin ve göknar meşcerelerinde daha önemlidir. Bu bakımdan Doğu Karadeniz bölgesindeki orman alanlarındaki diri örtü, gençleştirme çalışmaları sırasında oldukça önemli engeller oluştururlar (Demirci 2008). Bu nedenle Doğu Karadeniz bölgesi için Rhododenron ponticum'un hangi kapalılık derecesinde ne kadar gelişim yapabildiğinin ortaya konması önem taşımaktadır.
Bu çalışma, Doğu Karadeniz bölgesinde önemli gençleştirme sorunlarına neden olan Rhododenron ponticum'un (Mor Çiçekli Orman Gülü) 1, 2 ve 3. derece kapalılıktaki orman alanlarında dokuz yıllık çap ve boy artım değerlerinin belirlenmesi amacıyla gerçekleştirilmiştir.

\section{MATERYAL VE YÖNTEM}

\subsection{Araştırma Alanı}

Araştırma alanı; Artvin ili Artvin Orman İşletme Müdürlüğü Artvin Orman İşletme Şefliği sınırları içerisinde kalmakta olup Merkez Balcıoğlu Mahallesi sınırları içerisinde yer almaktadır. Şehir merkezine yaklaşık $10 \mathrm{~km}$ uzaklıkta bulunmaktadır. Araştırma alanı dağlık olup denizden ortalama yüksekliği 1650 metredir. Ayrıca çok sayıda dere mevcuttur. Arazi eğim derecesi \%0-100 arasında değişiklik göstermektedir (Şekil 1).

Alanda Doğu ladini, Doğu kayını, Sarıçam ve Doğu Karadeniz göknarı mevcuttur. Alanda ladin ve kayın saf meşçereleriyle beraber, yukarda bulunan türlerin birbirleriyle karışıklık yapan meşçereler mevcuttur. Toplam araştırma alanı yaklaşık olarak 2000 ha' dır.

Artvin Merkez Orman İşletme Müdürlüğünde 41.0842-55 kuzey enlemleri ile 41.4606 - 20 doğu boylamları arasında bulunan farklı kapalılık derecesine sahip orman alanlarındaki çalışma alanının materyalini ormangülü sahalarında $5 \times 5 \mathrm{~m}$ boyutlarında seçilen 49 adet örnek (Şekil 2) alanda yapılan 9 yıllık çap ve boy artımı oluşturmaktadır. 


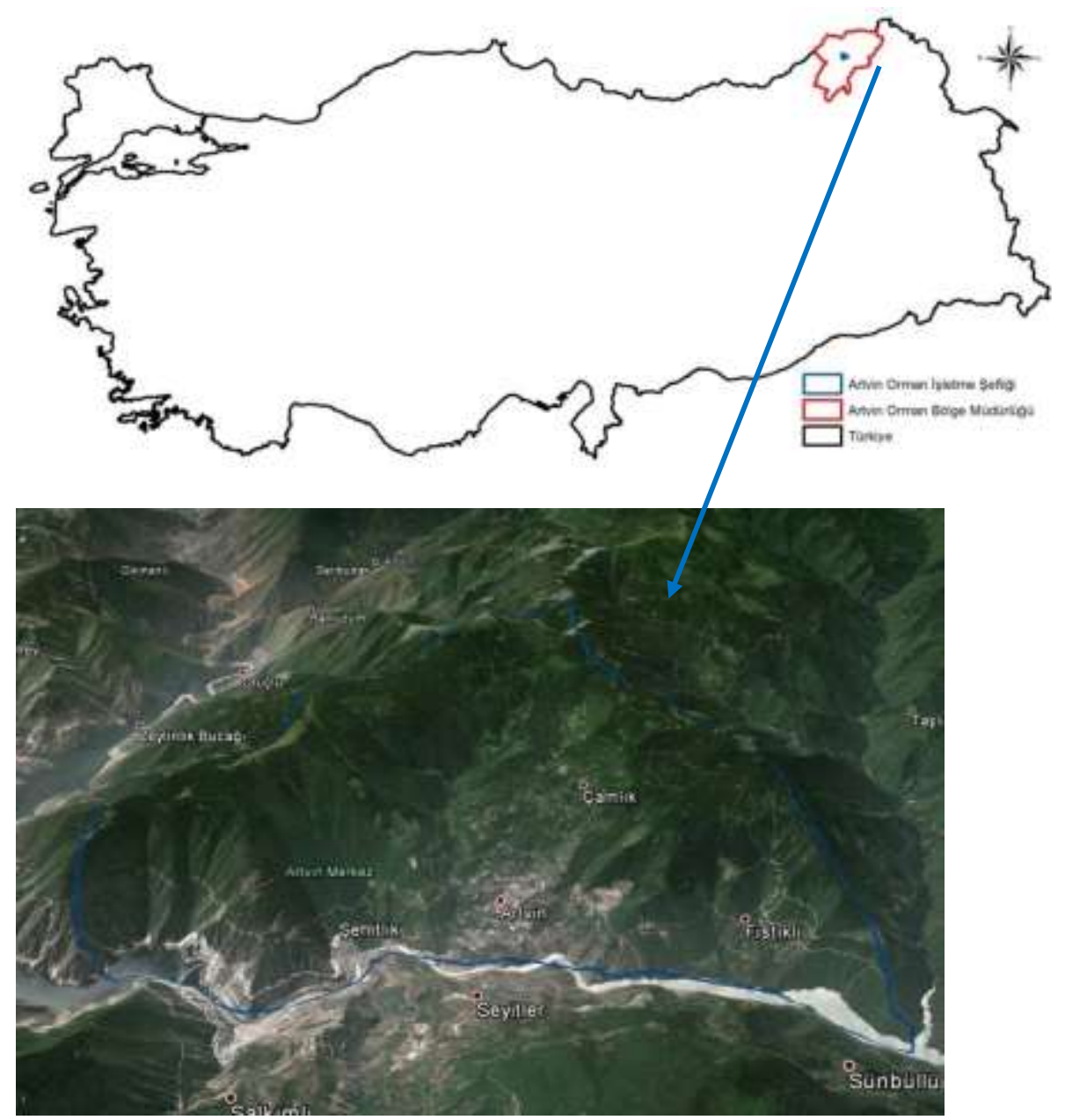

Şekil 1. Araştırma alanının görünümü

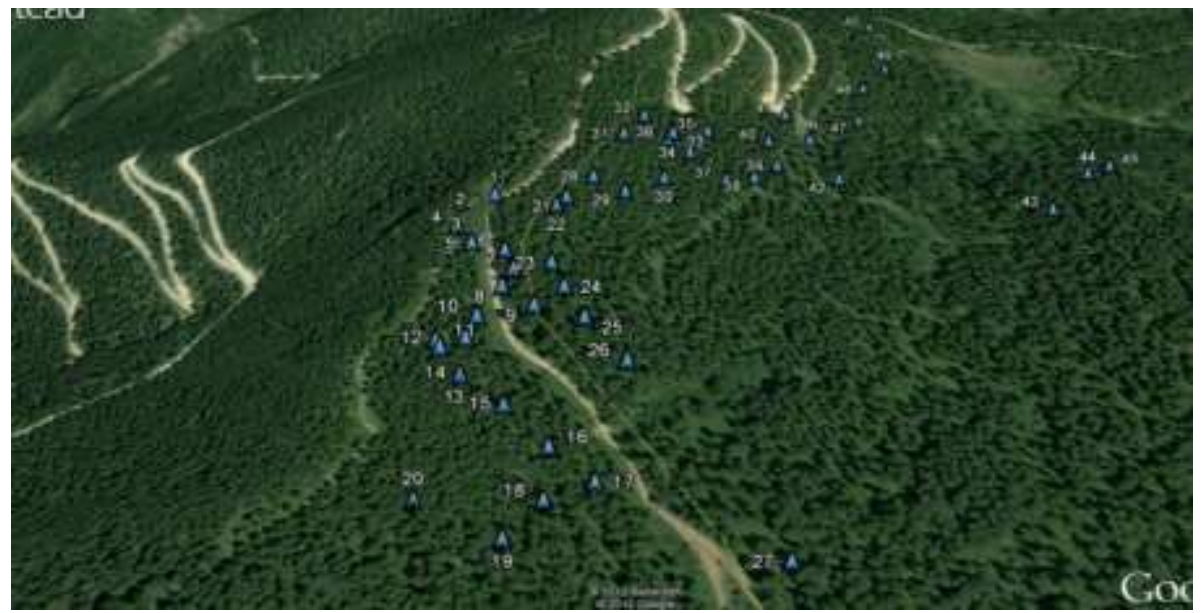

Şekil 2. Araştırma alanında 5 x 5 m büyüklüğündeki deneme alanlarının dağıımı

\section{Yapılan Çalışmalar}

Araştırma alanında ormangülünün kesildiği alanlardaki sürgünlerinin yıllık çap ve boy gelişimini belirlemek amacıyla rastgele (tesadüfi) örnekleme yöntemine göre deneme alanları seçilmiştir. Örnekleme noktalarının yerleri katmanlı rasgele örnekleme yöntemine belirlenmiştir (McGrew ve Monroe 1993).

Araştırma alanının tamamında kapalılık derecelerine göre toplam 49 adet olmak üzere $5 \times 5$ m ebadında araştırma parselleri seçilmiştir. Kapalııı bakımından ormanlar; 0- 
boşluklu kapalı (tepe kapalılı̆ı \% 10 ve daha az), 1- gevşek kapalı (tepe kapalılığı \%11-\%40'a kadar), 2- orta kapalı (tepe kapalılığı \%41-\%70'e kadar), 3- kapalı ve tam kapalı (tepe kapalılığı \%71-\%100'e kadar), 4- sıkışık veya grift kapalı (tepe kapalılı̆ı $\% 100$ 'den daha fazla), 5-dikine kapalı (seçme kuruluşundaki meşcereler için) şeklinde kapalıık sınıflarına ayrılmaktadır (URL-1). Bu çalışmada 1, 2 ve 3. kapalılık derecelerine göre alan seçimleri yapılmıştır. Kapalılık dereceleri tecrübeye dayalı tahmin (Genç 2004) belirlenmiştir. Tecrübeye dayalı tahmin yoluyla yapılan tespitlerde ağaçların tepe çatılarının arasında hiç boşluk olmaması veya tepe çatılarının birbirine temas etmesi durumu 3 (Tam) kapalı, ağaç tepeleri arasına bir ağaç tepesi sığacak kadar boşluk olması durumu 2 (Orta) kapalı ve ağaç tepeleri arasına iki veya daha fazla ağaç tepesi girebilecek kadar boşluk olması durumu 1 (gevşek) kapalı olarak değerlendirilmiştir.

Belirlenen örnekleme noktalarının enlemi, boylam, yükselti ve bakı özellikleri GPS cihazı ile belirlenmiş olup; eğimi, klizimetre ile ölçülmüştür. Belirlenen deneme alanlarına $5 \times 5 m^{\prime}$ lik alanı belirleyip sınırlandırmak için şerit metre kullanılmış ve sınırları belirlenen alanın etrafı iple çevrilmiştir. Oluşturulan $5 \times 5$ m'lik karenin içerisinden denk gelen tüm ormangülleri toprak seviyesinden kesilmiştir.
Bir yıl önce dipten kesilerek temizlenen deneme alanlarının, bir yıl sonra dip kütükten çıkan sürgünlerinin tümü dip kökünden milimetrik çap ölçerle ölçülerek 9 yıl boyunca çap ve boy artımı gözlemlenmiştir. Ayrıca sürgünlerin her birinin boyu milimetrik olarak ölçülmüştür. Sürgünlerin boyu çelik şerit metre yardımıyla, sürgünlerin çapı dijital kumpas yardımıyla belirlenmiştir.

Araziden çalışmalarından elde edilen veriler, Microsoft Excel 2018 paket programı yardımıyla veri tabanına işlenmiştir. Kapalılık derecelerine göre boy gelişimleri arasında fark olup olmadığını belirlemek amacıyla IBM SPSS (Statistic 21) paket programı kullanılarak basit varyans analizi (One-Way Anova) analizi yapılmıştır. Gruplar arasındaki farkın belirlenmesinde, çoklu karşılaştırma (Post-hoc) testlerinden Bonferroni testi uygulanmıştır.

\section{BULGULAR VE TARTIŞMA}

Meşcere kapalılık derecelerine göre mor çiçekli orman gülünün yıllık çap artımı (cm/ha) miktarlarında istatistiksel olarak anlamlı $(p<0.05)$ farklılıklar tespit edilmiştir (Çizelge 1). En fazla yıllık çap artımı $(1.23 \mathrm{~cm})$ gevşek kapalı meşcerelerde tespit edilmiştir (Çizelge 2).

Çizelge 1. Yıllık çap ve boy artımı Varyans analizi sonuçları

\begin{tabular}{|c|c|c|c|c|c|c|}
\hline & Kareler Toplamı & Serbestlik D. & Ortalama Kare & $\mathbf{F}$ & Önem Düzeyi & $\begin{array}{c}\text { Çoklu } \\
\text { Karşılaştırma }\end{array}$ \\
\hline \multicolumn{7}{|c|}{ Yıllık Çap Artımı(cm/ha) } \\
\hline Gruplar arası & 0.080 & 2 & 0.040 & 3.705 & .032 & \\
\hline Gruplar içi & 0.495 & 46 & 0.011 & & & $1-3$ \\
\hline Toplam & 0.574 & 48 & & & & \\
\hline \multicolumn{7}{|c|}{ Yıllık Boy Artımı(cm/ha) } \\
\hline Gruplar arası & 16.549 & 2 & 8.275 & 10.198 & .000 & \\
\hline Gruplar içi & 37.324 & 46 & 0.811 & & & $1-3$ \\
\hline Toplam & 53.874 & 48 & & & & $2-3$ \\
\hline
\end{tabular}

Çizelge 2. Kapalılık derecelerine göre tespit edilen ortalama artımlar

\begin{tabular}{|c|c|c|c|}
\hline & Kapalılık & Adet & Ortalama (cm) \\
\hline \multirow{4}{*}{ Yıllık Çap Artımı(cm/ha) } & 1 & 19 & 1.23 \\
\hline & 2 & 13 & 1.22. \\
\hline & 3 & 17 & 1.14. \\
\hline & Toplam & 49 & 1.20. \\
\hline \multirow{4}{*}{ Yıllık Boy Artımı(cm/ha) } & 1 & 19 & 7.58 \\
\hline & 2 & 13 & 7.16. \\
\hline & 3 & 17 & 6.24. \\
\hline & Toplam & 49 & 7.00 \\
\hline
\end{tabular}


Orman gülleri gelişim için ışığa ihtiyaç duymaktadırlar. Bu nedenle, Karadeniz de kapalıı̆̆ın kırıldığı alanlara orman gülü gelmektedir (Önal 2017). Mor çiçekli orman gülü diğer orman güllerinden farklı olarak gölgeye dayanabilmektedir. Tam kapalı (\%90) bir meşcerede bile alana gelip yerleşebilmektedir (Saatçioğlu 1957, Gritten 1995, Clinton ve Vose 1996, Çolak 1997). Bu çalışmada da mor çiçekli orman gülünün tam kapalı bir meşcerede gelişim gösterebildiği tespit edilmiştir. Diğer orman güllerinin gelişiminde olduğu gibi mor çiçekli orman gülünün gelişiminde de ışık önemli bir rol oynamaktadır. Tam kapalı bir meşcerede gelişim gösterebilmesine karşın en iyi çap artımını gevşek kapalılıkta yaptığı tespit edilmiştir. Yıllık çap artımları gevşek kapalııık derecesinden tam kapalılık derecesine doğru azalmaktadır. Yıllık çap artımı bakımından kapalılık derecesi grupları arasındaki farkın belirlenmesine yönelik yapılan çoklu karşılaştırma testlerinden Bonferroni testine göre 1 . derece meşcere kapalılı̆ı ile 3 . derece meşcere kapalılığı arasındaki bu farklılıklar istatistiksel olarak anlamlıdır (Çizelge 1, Şekil 3.

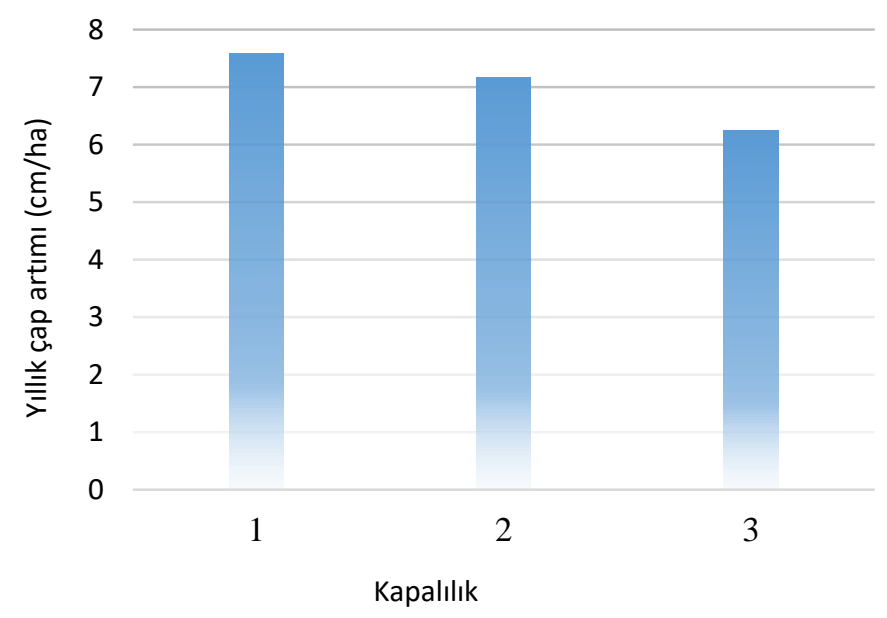

Şekil 3. Kapalılık derecesine göre yıllık çap artımı

Meşcere kapalılık derecelerine göre mor çiçekli orman gülünün yıllık boy artımı (cm /ha) miktarlarında da çap artımlarında olduğu gibi istatistiksel olarak anlamlı $(p<0.05)$ farklılıklar tespit edilmiştir (Çizelge 1). Ortalama yıllık boy artımı değerinin 1. kapalııı derecesinden 3. kapalılık derecesine doğru azalmaktadır (Şekil 4) Yıllık boy artımı, en fazla gevşek kapalı meşcerelerde $(7.58 \mathrm{~cm})$ en az ise tam kapalı meşcerelerde $(6.24 \mathrm{~cm})$ ölçülmüştür (Çizelge 2). Elde edilen bu sonuçlara benzer şekilde,
Montane ve ark. (2016), orman gülleri ile birlikte yayılış gösteren Vaccinium myrtillus (L) türünün boy büyümesinde kapalılığın artmasıyla birlikte azalmaların meydana geldiğini belirlemişlerdir.

Yıllık boy artımı bakımından kapalılık derecesi grupları arasındaki farkın belirlenmesine yönelik yapılan çoklu karşılaştırma testlerinden Bonferroni testine göre 1. derece meşcere kapalılı̆ı ile 3 . derece meşcere kapalılığı arasında ve 2 . derece meşcere kapalıığı ile 3 . derece meşcere kapalıı̆̆ı arasındaki farklılıkların anlamlı olduğu tespit edilmiştir (Çizelge 1).

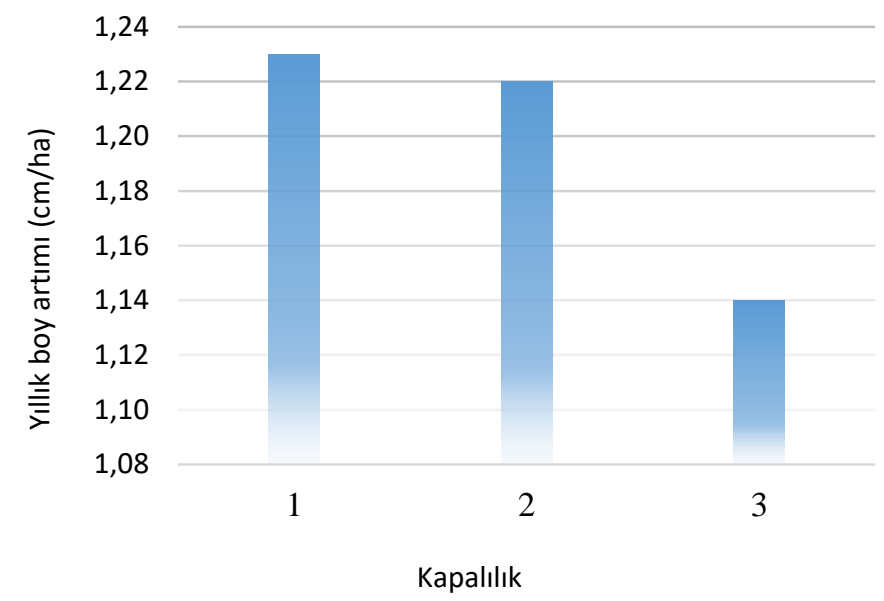

Şekil 4. Kapalılık dercesine göre yıllık boy artımı

Mor çiçekli orman gülünün gelişiminde ışık kadar nemin de önemli bir etkisi bulunmaktadır. Mor çiçekli orman gülü genellikle nemim olmadığı alanlardan kaçınmaktadır (Cross 1981). Tam kapalı meşcerede boy gelişimin az olması, kapalııı̆ıı artmasıyla birlikte hem meşcere içine giren ışık miktarının hem de yağış azalmasından kaynaklandığı söylenebilir.

\section{SONUÇ VE ÖNERILER}

Çalışma sonucunda yıllık çap artımı ile yıllık boy artımı $(\mathrm{cm} / \mathrm{ha})$ değerlerinin meşcere kapalıı̆̆ arttıkça azaldığı gözlemlenmiştir. Yıllık çap artımı ve yıllık boy artımı $(\mathrm{cm} / \mathrm{ha}$ ) değerleri en fazla gevşek kapalı meşcerelerde, en az ise tam kapalı meşcerelerde belirlenmiştir. Sonuçlar, çalışma alanı orman ürünleri üretim fonksiyonuna sahip olduğundan, gençleştirme çalışmalarında orman gülünün diri örtü olarak sorun haline gelmemesi için orman kapalılı̆ının fazla kırımaması gerektiğini göstermektedir. 


\section{KAYNAKLAR}

Avcı M (2004) Ormangülleri (Rhododendron L.) ve Türkiye'deki doğal yayılışları. İst. Üniv. Edebiyat Fak. Coğrafya dergisi, 12:13-39.

Clay DV, Goodall JS, Nelson DG (1992). The effect of imazapyr on Rhododendron ponticum. vegetation manegement in forestry, amenity and conservation areas, Aspects of Applied Biology,29: 287-294.

Clinton BD, Vose JM (1996) Effects of Rhododendron maximum L. on Acer rubrum L. seedling establishment. Castanea 61: 38-45.

Cross JR (1981) The establishment of Rhododendron ponticum in the Killaney Oakwoods, S.W. Ireland. Journal of Ecology, 69: 807-824.

Çolak AH (1997) Rhododendron ponticum L. (Mor Çiçekli Ormangülü)'un Silvikültürel Özellikleri Üzerine Araştırmalar, İstanbul Üniversitesi Fen Bilimleri Enstitüsü, Yayınlanmamış Doktora Tezi, İstanbul.

Çolak AH (1997) Rhododendron ponticum L. (Mor çiçekli ormangülü)'un silvikültürel özellikleri üzerine araştırmalar, İstanbul Üniversitesi Fen Bilimleri Enstitüsü, Yayınlanmamış Doktora Tezi, İstanbul.

Demirci A (2008) Orman Bakımı, Karadeniz Teknik Üniversitesi Orman Fakültesi Ders Notları Serisi, No:88, s. 115 Trabzon.

Genç M (2004) Silvikültürün Temel Esasları, Süleyman Demirel Üniversitesi Yayın No: 44, Isparta.

Gritten RH (1995) Rhododendron ponticum and some other invasive plants in the 33 Snowdonia National Park. In: General Aspects and Special Problems. Plant Invasions, 213-219.
Küçük M. (2005) Türkiye'nin doğal ormangülleri. Çevre ve Insan. 62: 23-31.

McGrew J, Monroe CB (1993) Statistical problem solving in geography. Oxford: Wm. C. Brown Communications.

Montané F, Guixé D, Camprodon J (2016) Canopy cover and understory composition determine abundance of Vaccinium myrtillus L., a key plant for capercaillie (Tetrao urogallus), in subalpine forests in the Pyrenees, Plant Ecology \& Diversity, 9 (2): 187-198

Önal G (2017) Mor çiçekli ormangülü (Rhododendron ponticum L.) biyokütlesinin belirlenmesi, Bartın Üniversitesi, Fen Bilimleri Enstitüsü, Yüksek Lisans Tezi, BARTIN

Robinson JD (1980). Rhododendron ponticum - A weed of woodlands and forest plantations seriously affecting management; Proceedings Weed Control in Forestry Conference. 89-95.

Saatçioğlu F (1957) Karadeniz Ormanlarında Süceyrat Problemi. Ayancık-Çangal Bölgesinde Mekanik Metotla Yapılan Süceyrat Mücadelesine Ait 12 Yıllık Tecrübe Neticeleri İstanbul Üniversitesi Or. Fak. Dergisi. 7(1).

Stewens PF (1978) Rhododendron L. Flora of Turkey and the East Aegean Island (Ed. P.H. Davis), Edinburgh University Press, Edinburgh. 6: 91-94.

Suzuki M, Ohba H (1988) Wood Structural Diversity Among Himalayan Rhododendron. lowa Bulletin. 9 :(4), 317-326.

Thomas M (2015) A review of understory response to changes in overstory conditions and community scale fuel break design in wet interior Cedar Hemlock Forests in British Columbia. Prepared for the Revelstoke Community Fuel Break Design Project. p 21. 